\title{
STEFFENSEN'S GENERALIZATION OF ČEBYŠEV INEQUALITY
}

\author{
K. M. Awan, J. PEČArić And ATIQ UR REhMAN
}

Abstract. In this paper, we obtain Ostrowski-type bounds for the weighted Čebyšev functional. Also we give bounds of weighted Čebyšev functional in the case of Steffesen's generalization of Čebyšev inequality.

Mathematics subject classification (2010): Primary 26D15, 26D20, 26 D99. bounds.

Keywords and phrases: Čebyšev functional, weighted Čebyšev functional, bounds, Ostrowski-type

\section{REFERENCES}

[1] P. Cerone And S. S. Dragomir, Some Ostrowski-type bounds for the Čebyšev functional and applications, J. Math. Inequal. 8, 1 (2014), 159-170.

[2] P. L. Chebyshev, Sue les expressions approximatives des inté grales définies par les autres prises entre les mêmes limites, Proc. Math. Soc. Charkov 2 (1882), 93-98.

[3] A. M. Ostrowski, On an integral inequalty, Aequat. Math. 4 (1970), 358-373.

[4] J. E. PeČARIĆ, On the Ostrowski Generalization of Čebyšev Inequality, J. Math. Anal. Appl. 102 (1984), 479-487.

[5] J. E. Pečarić, F. Proschan and Y. L. Tong, Convex functions, Partial Orderings and Statistical Applications, Academic Press, New York, 1992.

[6] J. F. STEFFENSEN, En ulighed mellem middelve edier, Mat. Tidsskrift B, 49-53. 